\title{
Sobre o sentido da Educação Ambiental: \\ QUESTÕES E REFLEXÕES
}

\section{About the sense of Environmental Education: Questions and reflections

\author{
Sobre lo sentido de la Educación Ambiental: \\ cuestiones y ideas
}

\author{
Sandro Cozza Sayão ${ }^{1}$
}

\begin{abstract}
RESUMO
Pensar sobre a Educação Ambiental, seu sentido e desafios em nosso tempo, é a grande tarefa deste artigo. O que proponho é mostrar e reafirmar o caráter crítico e reflexivo da Educação Ambiental, especulando sobre seu compromisso na criação de espaços nos quais se possa aprender a olhar, sentir, pensar, agir e conviver eticamente. A ideia central do texto gravita em torno do desejo de falar de um modo, de fazer educação alinhado à responsabilidade socioambiental, na qual o impulso à ampliação da consciência é capaz de nos conduzir a patamares em que a ética, a sensibilidade e o amor tornam-se elementos vigorosos do agir humano.
\end{abstract}

Palavras-chave: Educação Ambiental; ampliação de consciência; Filosofia da Educação.

\begin{abstract}
This article aims at discussing Environmental Education, the sense and challenges of the subject these days. Also, it presents and reasserts the critical and reflexive nature of Environmental Education, its commitment to create spaces where we learn how to observe, feel, think, behave, and live together ethically. The necessity of finding a way to educate that takes into consideration socioenvironmental responsibility is a core issue here since increasing socioenvironmental awareness means we can reach different levels of existence, levels in which ethics, sensitiveness and love become active elements of human attitudes.
\end{abstract}

Keywords: Environmental Education; awareness increase; Philosophy of Education.

\section{RESUMEN}

Pensar sobre la Educación Ambiental, su sentido y desafios en nuestro tiempo es la grande tarea de este artículo. Lo que propongo es enseñar y reafirmar el carácter crítico y reflexivo de la Educación Ambiental, explorando sobre su compromiso en la creación de espacios en los cuales se pueda aprender a mirar, sentir, pensar, actuar y convivir eticamente. La Idea central del texto gravita alrededor del deseo de hablar de un modo de hacer educación alineada a la responsabilidad socioambiental, en la cual el impulso a la ampliación de la conciencia es capaz de conducirnos a patamares donde la ética, la sensibilidad y el amor se convierten en elementos vigorosos del comportamiento humano.

Palabras-clave: Educación Ambiental; ampliación de la conciencia; Filosofía de la Educación.

1 Mestre em Educação Ambiental (FURG), Mestre em Filosofia e Doutor em Filosofia (PUCRS), Professor da Universidade Federal de Pernambuco. Email: sandro_sayao@hotmail.com. 


\section{Introdução}

\section{A experiência vivida}

Não resta dúvida que todo trabalho de extensão universitária é também um trabalho de pesquisa no qual saberes são tecidos, configurados e constituídos. Embora comumente a pensemos como um braço da universidade na comunidade, como mera ponte entre os conhecimentos produzidos pela academia e a sociedade, há que percebê-la para além deste papel secundário; mais que transmissora de informação, a extensão universitária é instância em que novos saberes insurgem, principalmente a alunos e professores que se dispõem a romper com posturas hierarquizadas e egocêntricas. A extensão universitária nos conecta ao nosso próprio tempo, às demandas dos dias que vivemos e à dinâmica do mundo do qual somos e fazemos parte. Nela abre-se uma forma direta de acesso à realidade, num processo de produção intelectiva que tem a vida como elemento primeiro. Aí, deixam-se de lado solipsismos e artificialismos, para se adentrar num entremear muito mais fiel com as coisas, com os entes e com os outros, no qual pululam idiossincrasias e movimentos. A extensão universitária é exatamente o acesso a esse estofo da vida, em que toda equação e toda lógica por melhor que sejam, são sempre precárias e insuficientes. Nela somos convidados a tatear essa sutil e invisível película humana no mundo, a que só os poetas e os mais sensíveis têm acesso. E pela sua proximidade com o que é e não com o que é dito ser, mostra-nos com os pés de barro, ligados umbilicalmente a dinamicidade própria do humano. E é por isso que a dizemos instância de abertura, donde gritam vozes mudas e sons imperceptíveis a ouvidos moucos. Há aí a exclamação de um saber que só é possível de ser acessado desde dentro, desde a articulação íntima com a vida e sua complexidade donde todas as teorias bebem sua inspiração e todos os grandes intelectuais calcam suas afirmações. Dessa relação íntima outro saber insurge, um saber igualmente importante e talvez mais relevante que todo saber que se tece na solidão de escritórios $e$ gabinetes ou em devaneios de mentes que se perdem em si mesmas desconectadas com o aqui em baixo. Na verdade, a extensão universitária não permite essa dicotômica ideia de um lá e de um lado de cá. Todo conhecimento é aí tecido a partir da dinamicidade nua e crua, desde suas entranhas e movimentos peculiares, sem formalidades e artificialidades. Toda formalização em dito é segunda e sem assepsias e desde dentro faz cintilar com todo seu vigor a dança da diversidade e da complexidade, fascinando quem tem olhos para ver e ouvidos para ouvir. E é neste espaço de vida que o outro mostra sua face. A extensão dá lugar ao outro que tradicionalmente não tem espaço nem vez e, por isso, se faz fonte de sabedoria. Nela a escuta e o acolhimento do mundo e das necessidades que o compõem são mais importantes que todo ensino que se possa fazer. Nesse espaço de encontro, em que saber e ignorância convivem a todo momento, aqui e acolá, aprende-se a aprender, aprende-se a ser, a fazer e a conviver. Talvez essa seja uma das maiores lições que a extensão pode deixar, a de percebermos que ignorância e saber são faces de um mesmo processo de busca, porque só busca quem é sábio o suficiente para se reconhecer ignorante - e não foi Sócrates, por acaso o homem mais sábio de seu tempo a afirmar - Sei que nada sei².

$\mathrm{O}$ que seriam das atividades de educação, da medicina, da enfermagem, da sociologia, da história, da biologia e de todas demais profissões, sem essa dimensão de abertura? Como se poderia pensar num bom profissional que não soubesse aprender com

Sócrates, um dos pais da filosofia conhecido pela frase: "sei que nada sei". 
a riqueza dos sentidos do mundo que o cerca, dessa polissemia que deixa espantado a quem nela se debruça? Como se poderia pensar num bom profissional sem a sensibilidade necessária para acolher a riqueza ao seu redor? A extensão universitária impede fechamentos tacanhos em si e nela se aprende que a vida é muito mais do que foi ou é dito, e que a história não chegou a seu ponto final como talvez nunca o chegue.

A extensão universitária se conecta ao fato de que há um saber que se acumula no modo como os sujeitos interagem consigo mesmos e com os outros e, que este só é acessível quando do encontro não hierárquico e indiferente para com estes e que há um saber que se produz quando do atravessamento do outro - do encontro com a alteridade e do encontro com o mundo. Isso como duas dimensões de possibilidades no qual aflui uma enorme riqueza ao conhecimento humano: uma que trata do acesso aos saberes sabidos das comunidades, saberes que em grande parte dos casos se encontram na esfera pragmática do agir cotidiano e que em razão de todo um academicismo cego e indiferente não toma corpo num dito explícito; e uma outra forma de saber que surge exatamente deste encontro com aquilo que não faz número com o mesmo, ou seja, do encontro com o outro, com o mundo, com a vida. O que se considera é todo um saber que se mostra na perspectiva de um conhecimento que se acessa de forma quase que hermenêutica no encontro com outras realidades e um outro que se produz pelo encontro com a diferença, pelo contato com o que nos excede, com que é outro em relação a nós. Daí, dizer-se da importância metodológica da escuta, do olhar atento, da hospitalidade e do acolhimento, como meios para se acessar essas dimensões do conhecimento $e$ para se dar margem à produção do novo, o que se dá na superação dos excessos de ativismos e da superficialidade em que só os grandes fatos têm valor. Em todo trabalho de extensão, assim como em todo trabalho de pesquisa, sabe-se que, na grande parte das vezes, são os fatos menores e mais sutis que mais importam e mais revelam. Como icebergs, os pequenos e sutis acontecimentos são como fontes reveladoras de questões maiores e de possibilidades mais complexas.

Neste sentido, o que trago aqui é o resultado de experiências vividas em atividades de extensão ligadas à Educação Ambiental, junto à Universidade de Caxias do Sul/UCS/RS e agora à Universidade Federal de Pernambuco/UFPE/ PE. Atividades estas que em muitos casos se resumiam a meros encontros de grupos humanos, grupos de debates, discussões e interações que se faziam no intuito de se refletir a respeito do nosso modo coletivo $e$ individual de viver ${ }^{3}$. A grandiosidade deste trabalho talvez esteja exatamente nessa singeleza, porque sua força estava exatamente na interação não hierárquica dos sujeitos que só queriam aprender. Assim, o que apresento é o registro e a discussão de alguns temas que se foram tecendo em idas e vindas teóricas nestes grupos e em vários momentos de reflexão voltados à significação e à tipificação dos objetivos e das metas destes mesmos encontros, num processo constante que tomava impulso na tentativa de não se incorrer em ativismos ou em técnicas e métodos inférteis, que dão impressão de se estar fazendo algo, mas que outra coisa não fazem senão mascarar e encobrir uma profunda estagnação e acomodação ao que aí está posto.

A Educação Ambiental nasce deste desejo pelo novo, na esperança de que através dos processos pedagógicos possamos construir outras formas de se agir e pensar, assim como de vislumbrar outras possibilidades à vida como um todo. No entanto, a repetição e a metamorfose

3 Junto ao Projeto Cidadão do Século XXI desenvolvido pela Universidade de Caxias do Sul os projetos de Educação Ambiental realizados atingiram mais de 1500 crianças e adolescentes, os cursos de extensão foram destinados a aproximadamente 80 pessoas e as atividades de Educação a Distância/NEAD/UCS a mais de 2.500 professores da rede pública. 
do já posto são como fantasmas que sempre nos rondam. Desde as primeiras iniciativas, que assumidas, sabíamos que não são raros processos que em muitos casos são muito mais atividades de adequação ao status quo, do que propriamente atividades promotoras do novo. Entenda-se aqui adequação como estagnação, inércia, imobilidade, processos em que se dá manutenção à forma comum de se pensar em que se mantêm intocáveis os elementos que sustentam nosso modo de ser no mundo, numa completa ausência de crítica e reflexão.

Daí, dizer-se que a tentativa de uma virada epistemológica/paradigmática significativa, numa real contribuição para se reconfigurar o comportamento humano, deva estar associado à análise e à busca constante de sentido. Sem um sentido claro, não há tecnologias e instrumentos capazes de tornar qualquer projeto significativo e profícua qualquer iniciativa. Como tão bem nos ensinou Sêneca ${ }^{4}$, não há ventos favoráveis para quem não sabe aonde quer chegar. Quando nossos objetivos não estão claros e quando não sabemos para onde se quer ir, tudo é irrelevante e sem importância. É como se estivéssemos em meio a um oceano de possibilidades, mas absolutamente estagnados, inertes pela pura falta de orientação. Assim é com nossa vida particular, assim é com o trabalho em extensão, e em nosso caso, com o trabalho em Educação Ambiental.

Orientamo-nos, pragmaticamente, a partir de determinados elementos que nos dão sentido e isso não quer dizer, no entanto, que tudo já deva estar pronto antes mesmo de iniciarmos as atividades pretendidas. Não se fala aqui de um sentido fechado, mas de um sentido aberto, dinâmico e acessível à mutação, no qual se permitem revisões e reconfigurações de metas. Paulo Freire ${ }^{5}$, em sua vasta obra, apontou para o fato de que o caminho se faz ao caminhar, de que tecemos nossos rumos com o próprio desdobrar das nossas ações, com as próprias experiências que vamos acumulando. Como entes de livre arbítrio nada nos prédefine e, com isto, tudo é passível de escolha, de mutação e transformação. Essa é a grandeza de todo trabalho de extensão, a abertura à possibilidade do novo, não em relação aos conhecimentos que tecemos, como no sentido da para a própria inovação dos rumos pretendidos. No entanto, se há uma dinamicidade, pode-se pensar agora num sentido maior de orientação que aceite a multiplicidade e a dinamicidade próprias do viver. E, por esta razão, dizer-se que em Educação Ambiental o sentido maior que a orienta é sempre o sentido ético, a pretensão da ética e da justiça para nossas ações.

Vivemos a insustentabilidade de todo um modo de vida. A crise em suas múltiplas faces mostra isso e nos ensina que estes fazem parte não de eventuais ações inadequadas, mas de todo um universo paradigmático que sustenta nosso modo de agir e pensar. Há um solo de valores, costumes, mitos, formas pensamento e de modos de agir sobre nossos pés, desde os quais se alimentam nossas ações. Neste, nosso agir se configura e deste é a fonte de nossos problemas. Por isso dizermos que nosso problema não é um problema que se resolverá unicamente pelo exercício da técnica. Temos forte tendência em acreditar que os problemas socioambientais de nosso tempo serão resolvidos pelo aperfeiçoar da técnica e pela evolução da ciência, que a crise no modo como lidamos com o mundo se resolverá pelo advir de novas tecnologias. Desconsideramos que são os valores, a cosmovisão e os paradigmas que nos orientam as fontes dos desastres existentes e que a técnica, em muitos casos, apenas responde a essas concepções de mundo em nada criticando os valores existentes. Basta olharmos para os

\footnotetext{
"Não há ventos favoráveis para os que não sabem para onde vão". Sêneca.

5 Ver os livros de Paulo Freire: Pedagogia do oprimido e Ação cultural para a liberdade.
} 
avanços da medicina que tentam sanar as doenças sem alertar para os modelos de vida que se têm. Lidam com a doença, mas esquecem de atentar para a saúde. Por isso, dizermos que nossos problemas são frutos dos paradigmas que lhe fomentam, como consequências de todo um modo de pensar, que tem no pensamento reducionista e linear sua grande razão de ser. Essas considerações nos remetem de saída para o fato de que não basta incentivar a produção de novas tecnologias sem pensar os novos rumos para esta. Isso para não vivermos numa eterna perambulação, como numa Samsara budista em que as coisas e os acontecimentos se repetem em razão de não se ter alterado profundamente nossa forma de agir e pensar ${ }^{6}$. Nisso a importância radical da educação, da sociologia, da filosofia e das artes de um modo geral. Sem a força argumentativa e transgressora dessas, somos entregues às armadilhas do status quo.

\section{A crise de sentido}

Dito isto é possível afirmar que o grande problema da Educação hoje é a carência de um sentido claro que a oriente, assim como de políticas públicas comprometidas que projetem metas e as cumpram. É fácil perceber tanto na análise das atividades desenvolvidas nas escolas públicas, como nas da rede privada, essa perda de sentido. Nas primeiras a carência financeira e o desânimo conduzem a uma total apatia, na qual pouco se faz e pouco se cria, nas outras a abastança que o dinheiro possibilita, cria uma cortina de fumaça que enche os olhos, mas têm pouca repercussão transformadora. São escolas que usam o "marketing" verde para atraírem a atenção dos pais e, com isto, novos "clientes", mas que mantém comportamentos e atitudes antiecológicas e antiéticas inalteradas. São escolas onde o discurso do corpo não condiz com o discurso da voz, e a incoerência é mola propulsora da indiferença e da completa falta de responsabilidade. Fala-se uma coisa e se faz outra e para comprovar essa dicotomia, basta olhar para o refeitório, para os valores cultivados, as condutas usuais existentes e para o próprio tratamento dos resíduos feitos diariamente, em grande parte o discurso não condiz com a prática.

Como já afirmei anteriormente, não são as metodologias o interesse maior aqui, mas o sentido que as fomenta. A explicitação deste, mesmo que precária, é com certeza mais útil $e$ inspiradora se incidíssemos sobre breves descrições. Antes, porém, como forma de orientar o leitor sobre que tipo de atividades fertilizaram as reflexões aqui presentes, destaco: o projeto de Educação Ambiental ligado ao Programa Cidadão do Século XXI da UCS, programa de fundo filantrópico que atendia semestralmente mais de 2.500 crianças e adolescentes da $5 .^{\mathrm{a}}$ a $8{ }^{a}$ séries da rede pública do município de Caxias do Sul/RS, com oficinas das mais diferentes ordens; a formação e capacitação continuada de professores e gestores ambientais via EAD (ligadas ao Núcleo de Educação a Distância da Universidade de Caxias do Sul), com compromisso de atender a população da região Norte do estado do Rio Grande do Sul (Região Serrana, Campos de Cima da Serra e vale do Taquari/Caí do estado gaúcho); a organização da Sala Verde - Gralha Azul, ligada ao Centro de Filosofia e Educação da UCS; projetos de Extensão, cursos e palestras ligados às prefeituras e ONGs e agora a participação no grupo de Ciência e Cultura de Paz da UFPE, no qual se trabalha sobre a subjetividade e a tessitura da paz.

\footnotetext{
6 Esse aprisionamento numa eterna perambulação é facilmente visto no sistema de saúde. Os hospitais estão repletos de eternos doentes. Que vivem a vida num vai e vem porque não alteram seus comportamentos que são os verdadeiros responsáveis pelo estado doentio. Curam-se hoje para logo adoecerem de outras mazelas. Vício da dor própria de uma fixação no que a gesta.
} 
Interessa frisar, que em todas essas atividades o que se buscou e busca é a aproximação de alunos, professores e gestores ao sentido maior das causas socioambientais, almejando uma reflexão profunda voltada à consolidação de caminhos que nos possam levar à superação da indiferença egocêntrica e narcisista que assola nosso modo de ser no mundo. O que se dá a partir da escuta atenta da crise de nosso tempo e da certeza de que é preciso uma ação interdisciplinar, multifocada, voltada ao redimensionamento de nossos valores e dos aspectos que sustentam nossas escolhas. Essa escuta aliada à constante discussão sobre o sentido pretendido, cria um élan capaz de nos orientar nas mais diferentes iniciativas, mesmo que essas não lidem especificamente com as questões naturais.

É um erro pensar que a questão ambiental se resume a discussão das relações com a natureza. É preciso ampliar essa discussão $e$ isso surge quando da ampliação do conceito de Ambiente. Normalmente por ambiente se entende o lugar dos entes vivos e não vivos. Ao se falar em ambiente se entende os ecossistemas. Mas o ambiente é também o lugar das relações humanas e sociais, é também o lugar e espaço não material em que se formam o pensar humano, ambiente mental. Daí dizermos que a crise socioambiental considerada atinge não apenas a esfera das nossas relações com a natureza, mas do modo como lidamos com a dimensão social e mental do mundo humano, no que Guatarri chamaria do escopo das três ecológicas ${ }^{7}$. Chamar atenção para isso é chamar atenção para o fato que, por ambiente humano, se entende o locus natural, social e mental do homem e que a crise de cada uma dessas instâncias é, na verdade, a crise de um mesmo universo de sentido em que reverbera nosso modo de ser no mundo. Por trás dos problemas manifestos e observáveis, há uma trama e jogos de poder e controle. E é para lá que se deve olhar quando da pretensão de focalizar nossas ações. É um erro pensarmos que os problemas ambientais se resumem ao contexto das nossas relações com o meio natural e de que estes são resolvidos por meio da técnica e dos avanços científicos. Há uma falsa ideia de que a questão ambiental é apenas uma questão voltada à busca de novas tecnologias para o modo como lidamos com a natureza natural, pois em grande parte das vezes isso não nos permite observar que o que é preciso mudar é nosso modo de estar no mundo e com isso, nossos interesses e nossos desejos. A violência, as guerras, a opressão, a miséria, a exploração de homens e mulheres, a superficialidade e a vulgaridade, os preconceitos, a vaidade e o egoísmo, o luxo que se sustenta pela exploração a todo custo, o imediatismo, a abstância de uns, e as discrepantes diferenças sociais, entre outras formas de desrespeito para com a vida, são frutos de uma mesma lógica e de uma mesma racionalidade desastrosa, "fechada em si", egocentrada e indiferente ao outro e profundamente narcisista. Embora nos acompanhe a muito, essa é uma chaga viva que devemos eliminar, o que exige uma vigorosa atividade crítica, reflexiva, ao mesmo tempo, que amorosa.

Não sou destes que caminha no pessimismo, embora não desconheça as misérias existentes. A meu ver, a mudança exige o vigor da alegria, a leveza capaz de transmutar pensamentos e ações ${ }^{8}$. Isso, porque nada é mais subversivo do que a generosidade e o acolhimento do outro no processo educativo. Perceber as necessidades alheias, descentrarse de si mesmo, sintonizar-se com o drama e acolher as carências dos outros, abrir-se para

\footnotetext{
Ver GUATARRI, Felix. As três ecologias. Campinas: Papirus, 1990.

8 No futuro me explicarei melhor a esse respeito.
} 
o que a ação do outro reclama, é um dos caminhos para que se instaure o que Guatarri chamou de "ecosofia". Daí, penso ser possível embrenhar-se nas tramas estéticas e éticas nas quais poderemos nos sensibilizarmos para a busca respeitosa de uma outra forma de ser e estar no mundo. E aqui se pode perceber que a informação não é necessariamente elemento articulador de novos comportamentos e que não basta estar esclarecido para mudarmos nosso modo de ser.

Sobre nós pesa uma malha mítica de formas/pensamento, que nos foram ensinadas desde nossos primeiros suspiros. Recebemos uma programação cultural/ideológica que não é de fácil desagregação. São vícios tornados carne, que exigem um trabalho profundamente crítico e reflexivo, associado à sensibilização e ao exercício do reconhecimento e do acolhimento do outro e de suas necessidades, assim como da percepção de que é possível ser diferente. $\mathrm{E}$, então, a importância pedagógica da extensão universitária que mostra e cultiva formas alternativas de vida. Daí a ideia dizer que antes de tudo precisamos cultivar a abertura - a "escuta". Escutar, acolher, hospedar o que não se é, para daí organizar, agir e falar - isso quase como a Shemá hebraica, que deve ser sempre a primeira e a última palavra a ser pronunciada ante o começo da vida e o começo da morte. Escutar, acolher, hospedar talvez esses sejam desafios à Educação hoje. O que é algo estranho num universo guiado pelo egocentrismo narcisista, onde o que vale são regras de classificação $e$ ordenação baseadas em alegorias e adornos míticos do que é e do que deve ser.

Desde Parmênides, há mais de 2500 anos, aprendemos que o ser é e o não ser não é. Essa ideia nos avilta, nos fecha e nos formata para o fato de que uns são e outros não, de que umas coisas são e outras não. E essa formatação se desdobra em profunda indiferença ao que não respeita às regras, aos modelos $e$ as formas do Mesmo. Há pessoas fechadas em seu universo particular, padecendo do que chamo do "mal de si", numa cegueira absoluta que às leva ao total encarceramento logocêntrico. O egoísmo é a ótica. Fechadas em si, e sem consciência, ao menos uma consciência crítica, resumem suas vidas ao exercício cego e fruitivo de uma racionalidade na classificação e na ordenação do real e que se compraz pelas conquistas que realiza. Em outras palavras, é Ego cogito que se confunde com Ego conquiro - que acaba por se desdobrar em violência, brutalidade $e$ indiferença. Agimos, pensamos e ordenamos nossa realidade sobre esse dispositivo e daí se perceber que o processo educativo deve lidar com termos e questões muito mais elementares da condição humana, que tem a ver com o próprio fundo ideológico que nos tipifica no mundo. Compreender isso é compreender a necessidade de tatearmos o modo como organizamos nosso próprio modo de ser no mundo. É esse que precisa ser tocado.

\section{O sentido - O termo ambiental em análise}

A partir disso tudo, podemos entender em que medida se tornou necessário agregar à educação ao termo ambiental. Por mais simples que isso possa parecer, a ideia de entender a agregação dos termos é altamente pertinente e importante. Ela nos remete ao significado da expressão como um todo, o que é de fundamental importância para quem se preocupa em evitar as armadilhas da obviedade e o risco de novas teorias que outra coisa não fazem senão a manutenção do status quo.

\footnotetext{
9 Para Guatarri é necessária uma recomposição das práticas sociais e individuais nas três dimensões que considerei acima, isso sob a égide ético-estética de uma ecosofia. Cf. GUATARRI, Felix. As três ecologias. Op cit., p.23.
} 
O termo ambiental, agregado à Educação, faz na verdade uma reivindicação de sentido. Ele tem por finalidade a re/significação de processos e ações pedagógicas que costumeiramente são surdos às necessidades do nosso tempo, chamando atenção para as causas socioambientais e para todas as discussões que se fazem a esse respeito. Embora não pretenda aqui traçar um histórico da Educação Ambiental, há que se considerar que ela surge desde as discussões de Estocolmo/1972, alinhada à tomada de consciência da insustentabilidade das escolhas vividas e como resposta ao cenário mundial de exploração e aviltamento das muitas formas de vida e dos ecossistemas. Através da Educação Ambiental se pretende a imersão num contexto ético desafiador, no qual a crítica, a reflexão, alinhadas à bagagem cultural acumulada, servem de trampolim à criação do novo. A ideia é projetar o processo pedagógico para além dos mecanismos de controle da lógica reducionista-utilitarista, apontando para a necessidade da gestãoética de processos nos quais possamos constituir um novo comportamento $e$ um novo modo de ser, mais ético e mais estético, em que o acolhimento e a própria receptividade sejam antes que a ação. O que demonstra uma concepção mais ampla do que se entende por Educação. Aí se percebe que educar é muito mais do que a transmissão de dados e informação $e$ se compreende a necessidade da instauração de instâncias críticas e reflexivas, em que se busca a transposição das estruturas reducionistas, logocêntricas e narcisistas que sustentam a indiferença em relação ao outro, no cultivo do que chamo de ampliação de consciência. Isso a partir da criação de condições para se alargar a compreensão a respeito do mundo e da realidade que se tem, a ponto de se enxergar no ordinário o extraordinário, no comum e no cotidiano, coisas que todos olham, mas não veem.

Daí, que a junção dos termos que analisamos apontem para a necessária sintonia do processo pedagógico à grande questão socioambiental, seja ela: a necessidade de transformação ética de nosso modo de agir e pensar. E aqui se percebe o processo educativo ultrapassando o tradicional centramento na aprendizagem e reprodução dos saberes sabidos, para o encontro crítico, criativo e ético com a realidade e o mundo. Se antes, a educação era sinônimo de ensino e aprendizagem, centrados na absorção passiva do conhecimento, a Educação Ambiental vem mostrar o necessário encontro ético e crítico com a realidade, na promoção de um agir e pensar ecologicamente sustentável. Nisso faz da dúvida instrumento pedagógico, abrindo espaço para a incerteza, num contexto de profunda problematização não só da realidade, mas de si mesmo. Em outras palavras, o olhar para fora é agora acompanhado de um constante olhar para si mesmo. Aí, a bagagem cultural é tão importante quanto o exercício da sensibilidade, da responsabilidade, da reflexão e da crítica. A ampliação de consciência é nisso, a consolidação de um sujeito reflexivo e crítico, que pelo exercício do descentramento e da saída de si, num processo em que se busca compreender a realidade pari passu a busca por compreender a si mesmo se mostra não indiferente ao outro e na capacidade de acolhimento. Fala-se aqui num processo em que os sujeitos são estimulados e provocados a olharem para além de suas próprias necessidades as necessidades dos outros, abrindo-se para o que está para além deles mesmos. Isso, num clima de profunda criatividade em que se cultiva a possibilidade de projetar o novo, conhecendo outras realidades e na certeza de que tudo no universo das escolhas humanas pode ser pensado e reconfigurado. Por esses processos, convoca-se o erguer de uma nova consciência, capaz de estabelecer conexões e de produzir conhecimento através da análise atenta do mundo e da abertura ao outro, porque vigora num contexto em que a complexidade e as interdependências não são sufocadas.

A partir disso, a junção do termo Ambiental à Educação representa o desafio 
de se fazer do encontro pedagógico instância de reconfiguração de nosso modo de pensar e ser diante dos outros, do mundo e de nós mesmos, via instauração da responsabilidade como pronto primevo, o qual emerge de um foco de reconfiguração de sentido em que cintila um caráter político e revolucionário muito mais do que informativo. Revolução como remexer de nossas certezas e dos aspectos míticos que nos cercam, na certeza de que não podemos continuar cultivando mitos que dizem de um desenvolvimento a todo custo, da natureza como almoxarifado de recursos e da ideia da sempre existência de miseráveis e pessoas excluídas. As verdades conhecidas $e$ as promessas de felicidade baseadas no desenvolvimento a todo custo se desagregaram no ar quando percebemos que há vidas desperdiçadas, que a natureza é brutalmente espoliada pelos modelos vigentes e que nós mesmos nos degradamos, enquanto sujeitos, dentro das estruturas civilizatórias baseadas no consumismo e na superficialidade.

Deste modo, a Educação Ambiental se configura para que se instale um modo de fazer pedagógico muito mais voltado ao pensar e ao refletir do que a necessidade de reprodução e de manutenção de estruturas e concepções já conhecidas. A Educação aqui passa a ser muito mais espaço de abertura para a produção do saber, da sensibilidade e da fraternidade do que propriamente transmissão da bagagem cultural acumulada. Muito mais questionadora e reflexiva do que reprodutora, a Educação aí transcende a necessidade de adequação dos sujeitos a um determinado modo de pensar e se mostra promotora da criticidade, da desconfiança e da especulação a respeito dos valores, das certezas e das regras existentes. Em outras palavras, o clamor da crise socioambiental promove o alinhamento da Educação à preocupação ética eà responsabilidade, o que vai indicar a importância do saber sabido e domínio, ao mesmo tempo, que uma profunda atitude de rebeldia para o já posto. E por isso, se dizer que nasce aqui uma prática pedagógica comprometida com a vida, disposta para além das áreas de silêncio que comumente a tornam alheia ao que aí está dado, numa dinamicidade que chamo de educação profundamente ambientalizada, mesmo que versando sobre questões abstratas de cunho não pragmático.

Não há tempo nem lugar para devaneios ou para uma educação amorfa, que cultive distanciamentos e questões superficiais. Entenda-se uma educação amorfa aquela que se faz sobre o cultivo de dados inertes ou de discussões vazias que não promovem a construção de novas atitudes diante da vida. A intenção aqui é evitar falas que não se "carnificam", discursos que não tomam corpo e que pouca repercussão fazem sobre os sujeitos humanos, a não ser se tornarem elementos às conhecidas sabatinas. Mesmo que a contradição seja uma realidade e que dificilmente façamos tudo o que pronunciamos, é preciso ao menos ter a responsabilidade pela tentativa de fazê-lo. $\mathrm{E}$, por isso, sou destes que defendem a Educação Ambiental, mesmo das acusações que a tentam diminuir rotulando-a de ser mais um "modismo". Para mim, essa questão não é pertinente. Atrelado à educação, o termo ambiental faz cintilar o fato de que estamos aí, que estamos imersos num mundo e nos desafios do nosso tempo e que por mais que nossas consciências busquem um lugar imaginário, é impossível fugir do fato de que precisamos cuidar da nossa casa planetária e que precisamos estar atentos a nossas escolhas. É como se houvesse um clamor que nos impulsionasse para que nos atentemos aos hábitos individuais e coletivos, aos valores e aos costumes, aos desejos e aos paradigmas a que a humanidade está acostumada.

A Educação Ambiental convoca à necessidade de percebermos nosso entorno e que neste mesmo entorno existem ações profundamente violentas e opressoras que precisam ser transformadas, repensadas $e$ 
reconfiguradas. E esse movimento é, para mim, instância de "aterramento", que nos ensina sobre a necessidade de perceber a fragilidade da vida a ponto de aprendermos sobre a necessidade de abdicar em favor do outro, de nosso próprio poder de poder. Por tudo isso, que a Educação Ambiental abre, no tempo e no espaço, uma instância reflexiva para discutirmos, analisarmos e repensarmos a vida e a nós mesmos tornando evidente a necessidade do que chamo de cultivo do descentramento. É preciso sair de um contexto em que pesam sobre nós o egoísmo e o fechamento sobre si, na forma de vaidade e culto à superficialidade, para se aprender a ouvir a vida em suas muitas manifestações e aos outros em suas necessidades.

\section{Considerações finais}

Por este motivo, agregar à Educação o termo Ambiental é não só dizer da necessidade de se criarem laços e desdobramentos, como de nos tornarmos conscientes da falência dos paradigmas vigentes. Penso que a Educação Ambiental busca trazer para dentro dos contextos pedagógicos a vida que fica do lado de fora, a vida e a realidade que insistimos em negar. Pelos seus muitos dispositivos, ela pauta-se pela superação do paradigma dicotômico e reducionista, materialista e desespiritualizado dos nossos dias. Isso a partir da vidência da complexidade no intuito de revolver costumes, promovendo o repensar de nossas escolhas e os esquemas pelos quais nos guiamos. Poderíamos tratar dos estados físicos da matéria, das planárias e dos números imaginários, entre outros saberes, desde que esses estivessem conectados a aspectos reflexivos que estimulassem o pensar e não só a decoreba. A necessidade é por criar espaços em que a busca pelo conhecimento específico $e$ especializado não perca de vistas a necessidade de buscarmos a melhoria da qualidade de vida para todos e a dignidade humana. A meu ver a ambientalização do saber evidencia o necessário atravessamento da educação pela ética e pela responsabilidade na perspectiva de se cultivar, junto às novas gerações e às que já estão aí, o desejo por um mundo melhor. Por tudo isso, vê-se que a Educação Ambiental é a resposta ao chamado, para que a produção do conhecimento se associe à necessária mudança de comportamento e à necessária transformação de nossos valores e nossos pensares. Não há tempo nem lugar para devaneios ou para uma educação amorfa. O tempo urge e é preciso olhar para nós mesmos, para nossas escolhas, desconfiar da lógica vigente, buscar um outro modo de vida. É deste lugar que penso ser viável falar numa Educação Ambiental, ou seja, numa Educação disposta à construção de um mundo mais justo e digno, no qual todos são bemvindos e no qual a responsabilidade é tônica central. Uma educação que não se confunda com treinamento, mas que inspire sonhos, que não se prenda a adaptações, à realidade circundante, mas que estimule a seleção ética do que importa e do que deve ser descartado; uma educação que saiba estimular olhares, que saiba da necessidade de não se cristalizar em verdades perpétuas, seja lá o que for; uma Educação que saiba que tudo é passageiro, desde os cargos até as verdades. Para muitos, isso não passa de sonho, para esses pergunto: do que é feita a vida senão de sonhos que se concretizam e de utopias que nos levam adiante? Se em algum lugar e em algum tempo a paz foi possível, se em algum recanto a generosidade mostrou sua face, podemos almejá-la e lutar por ela. Se em algum lugar o respeito à vida foi viável é possível cultivá-lo. É desta certeza que as almas corajosas abrem suas asas como as águias ao desafio do abismo e é nela que devemos buscar forças para lutar por um mundo melhor, mais sustentável e digno, mais ético e responsável a todos. 


\section{REFERÊNCIAS}

ADORNO, Theodor. Educação e emancipação. São Paulo: Paz e Terra, 1995.

FREIRE, Paulo. Ação cultural para a liberdade. 4. ed. Rio de Janeiro: Paz e Terra, 1979.

Educação e mudança. Trad. Moacir Gadotti e Lilian Lopes Martin. Rio de Janeiro: Paz e Terra, 1979.

Pedagogia do oprimido. 17. ed. Rio de Janeiro: Paz e Terra, 1987.
GRÜN, M. Ética e Educação Ambiental: a conexão necessária. 11. ed. Campinas: Papirus, 2007.

GUARESCHI, P. A consciência moral emergente. Aparecida, SP: Editora Santuário.

GUATARRI, Félix. As três ecologias. Campinas: Papirus, 1995.

SAYÃO, S. C. A Educação e a necessidade de novos territórios existenciais ao humano. In: . Filosofia e sociedade: Ijuí: UNIJUÍ, 2007, p.295-308.

Texto recebido em 16 de fevereiro de 2009. Texto aprovado em 27 de março de 2009. 